\title{
绿色发展理念下水电站标准化建设管析
}

张兆雄

玉林市农村水电及电气化发展管理站

DOI:10.32629/hwr.v4i1.2702

[ 摘 要] 加强水电站标准化建设,既是提升水电站建设与运行质量的内在要求,也是提升水电站经济、社会与生态效益的必由路径。基于绿色 发展理念,应通过强化标准化意识、确立标准化目标、发挥标准化效益,推动水电站标准化建设与高质量发展。

[关键词] 水电站; 标准化; 建设; 绿色发展

加强水电站标准化建设, 既是提升水电站建设与运行质量的内在要求, 也是增强水电站经济、社会与生态效益的必由路径。2016年以来, 我国出 台了发展 “绿色小水电” 的指导《意见》(水电 [2016]441号), 明确了发展 “绿色小水电” 的重要价值、总体要求、重点任务和保障措施。基于绿色 发展理念, 如何加强水电站标准化建设, 已成为一个重要的理论命题与实 践课题。

\section{1 绿色水电站的界定}

作为一种新发展观念, “绿色发展” 是一种和谐性、系统性、环境 开发与保护相统一的发展观, 也是生态文明建设的核心价值理念和基本 遵循 ${ }^{[1]}$ 。绿色水电站, 即是绿色发展理念在水电站建设和发展中具体体现 和生动实践, 但作为一个概念, 其内涵主要是指以和谐性原则、系统性原 则和生态保护原则建设和发展水电站, 在推动经济社会发展的同时, 推 动和优化生态环境, 以实现水电站与自然生态、社会生态和谐共生的局 面。在水电站建设和发展中, 由于经济条件限制、技术水平制约、规划 设计不够科学、管理机制缺失, 加之生态意识的薄弱, 导致一些河流 “减 水脱流”, 既给下游生产生活用水带来了不良影响, 也给生态环境带来了 一定破坏。建设和发展绿色水电站, 其目的就是转变水电站建设和发展 方式, 提升水电站建设和发展质量, 为经济社会发展创造和提供良好的 生态。

\section{2 水电站的标准化内涵及其价值}

所谓标准化, 即是 “研究解决应用问题办法的活动”, 通过获得 “最佳 秩序”, 降低产品成本、提升产品质量, 进而赢得更多更大的经济与社会效 益 ${ }^{[2]}$ 。水电站的标准化是一个系统性的工程, 包括的内容规划、设计、资 源论证、安全运行、管理、技术、评估等方面的标准化。前, 许多研究者 基于不同层面分析和探讨水电站的标准化, 比如, 刘建文等基于安全管理 的视角, 分析了水电站标准化的内容包括生产管理、制度建设、设备管理、
人员管理等内容 ${ }^{[3]}$; 赵立强基于质量建设的视角, 认为水电站质量标准化 主要包括技术标准、施工标准、管理标准等 ${ }^{[4]}$ 。由此可见, 水电站的标准 化具有丰富的内涵, 应把标准化理念融入水电站建设与发展的各个环节, 以标准化提升水电站的建设质量与发展质量。

加强水电站标准化建设, 具有极其重要的价值。从民众需要看, 随着 社会主要矛盾转化, 民众生活 “美好” 需求不断升级, 不仅对河流功能需 求日渐多样化, 而且空气、水质、环境也提出了更高要求。加强水电站 标准化建设, 就是通过调整其功能, 满足民众生产、生活、景观、生态用 水的需求, 提升民众的获得感。从发展理念看, “绿色发展” 已成为水电 站高质量发展的必由路径。但目前, 一些水电站的建设和发展, 存在着空 间布局不够合理、发展方式较为传统, 其发电效益往往是建立在损害生 态环境基础之上的, 不仅给生态环境带来一定破坏, 而且也导致自身发 展的不可持续性。加强水电站标准化建设, 就是通过改变水电站不合理 的发展方式, 使之在尊重、顺应和保护自然中, 走出一条高质量发展的路 子。从供给侧改革要求, 新一轮的能源供给消费革命, 要求水电站的建设 和发展坚持 “质量第一效益优先” 原则。目前, 我国人均用电量水平较 低, 2016 年为 4294 千瓦时/人, 仅为韩国人均用电量的 $2 / 5$ 、美国人均用电 量的 $1 / 3$ 、加拿大的 $5 / 18$ 。加强水电站标准化建设, 就是通过深化水电站 供给侧改革, 深入推进标准经开发、建设和管理, 提升水资源整体效益, 实现水电站的可持续发展。

\section{3 基于绿色发展理念的水电站标准化建设的路径}

近年来, 我国十分重视水电站标准化建设, 继水电 [2016] 441 号发布之 后, 先后出台了农村水电增效扩容的 “指导意见” (水电 [2016]60号)、绿 色小水电 “评价标准”、水资源 “论证导则” 等, 建立了较为完善的水电站 标准化体系。加强绿色水电站标准化建设, 就是按照上述技术标准, 打造高 质量的水电站, 推动其健康持续发展。
作中, 经常会出现转包或是分包等问题, 并且由于施工单位工作人员素质 较差, 专业技能有限, 很多工作的开展都可能受到不同程度的影响和限制。 所以工程建设方也需要加强不同阶段的联合验收, 这也是对工程质量水平 进行提升的基础保障。

\section{4 结束语}

综上所述, 在当前我国社会整体发展水平全面提升背景下, 不同地区 的经济发展水平已经有了较为显著的发展和提升, 所以在全新社会背景下, 怎样加强对渭河流域的综合治理也是当前我们研究和探索的重点环节。渭 河综合治理工作的顺利开展, 不仅能对渭河生态环境起到改善, 还能切实 提升周围城市的发展水平, 降低群众生命财产损失。渭河综合治理工作的 稳定开展, 对关中地区经济发展提供有效帮助, 推进陕西地区的跨越性发 展, 对于新兴产业和经济形势都将起到十分显著的积极影响。总而言之,
渭河综合治理工作的开展可以带动全省经济更稳定的实现进步, 所以在当 前社会发展水平全面提升背景下, 我们更应该加强对渭河综合治理工作的 关注和重视。

[参考文献]

[1]赵宏章,刘䂀.浅谈渭河堤防工程建设中格宾网施工技术与质量控 制[J].大坝与安全,2014,52(2):53-55.

[2]刘伯栋.渭河综合治理工程建设中的质量控制 [J]. 陕西水 利,2015,33(6):64-65.

[3] 薛双栋.论渭河综合治理工程建设中的质量控制 [J]. 建筑工程技术 与设计,2016,14(13):1574.

[4]王显,唐伟,张龙军.六千排综合治理工程建设主要做法与经验 [J]. 山东水利,2017,26(9):7-8. 
首先, 强化标准化意识。人与自然相和谐, 是绿色发展理念的核心价值 取向。就水电站标准化建设而言, 其目标的实现, 得益于员工与水电站标准 化的和谐。绿色水电站标准化建设, 归根结底依靠人, 只有培育人的标准和 规范意识、充分发挥人的积极性、挖掘人的创造潜能, 才能达成绿色水电 站标准化建设的目标。在这方面, 浙江省在推动水电站标准化建设中为我 们提供了重要启示 ${ }^{[5]}$ 。其做法是: 在理念上, 强调人人参与, 强化人的标准 意识、规范行为; 在计划上, 制定了 “水电站标准化达标评级实施办法”, 既明确了达标评级的具体标准, 也明确了具体的工作计划, 为员工提供了 明确的可操作性的行动标准和目标标准; 在指导上, 编制了图文并茂的指 导手册, 有效解决了员工为什么做标准化、怎么做标准化、做成什么样的 标准化问题; 在服务方面, 注重为员工提供系统性、有效性、优质性服务, 比如, 为解决技术难题, 一方面, 通过聘请专家举办培训班、宣贯班, 传授相 关技术知识与操作技能, 并实地面对面与指导, 另一方面, 通过 “一对一联 结” “以大帮小” 等方式, 以强带弱, 有效提升了员工的技术能力与合作能 力; 在氛围上, 通过实地学习观摩、建设安全文化、竞争比赛, 营造了浓厚 的 “比学赶超” 的良好氛围; 在管理上, 通过明确水电站标准化创建责任、 强化创建工作考核、完善经费保障、建立长效机制等, 推动水电站标准化 建设管理标准化与规范化。这一经验做法启示我们, 应把教育与实践有机 结合起来, 以标准化意识建设标准化, 在标准化建设升化标准化意识, 以此 推动水电站标准化建设和发展。

其次, 确立标准化目标。绿色发展的终极目标, 在于不断适应和满足民 众美好生活的需要。在绿色发展理念观照下, 推动水电站标准化建设, 应推 动水电站安全化、高效化、创新化、和谐化、秀美化发展, 实现经济效益 与生态效益的共赢, 增强民众的获得感与幸福感。所谓安全化, 即是通过水 电站标准化建设, 不断更新完善水电站设施设备, 提升其安全保障能力, 促 进水电站生产安全、有序; 所谓高效化, 即是落实 “效益优先” 观念, 通过 水电站标准化建设, 推动水电站安全生产、优化生态、美化环境, 实现水电 站的持续性增值; 所谓创新化, 即是通过水电站标准化建设, 不断完善水电 站的各项规章制度, 推动各项工作标准化、规范化, 使标准与规范成为每一 名员工的自觉与习惯; 所谓和谐化, 即把文化建设纳入水电站标准化建设 之中, 通过加强自身文化建设, 对内提升水电站的凝聚力和向心力, 外对树 立形象、争取社会大力支持, 从而赢得水电站发展的强大动力; 所谓秀美
化, 即是充分利用水电站所处的地理环境和资源, 不断优化水电站内部与 周边环境, 使之成为美化自然环境的一个支撑点、平衡生态关系调配器。

再次, 发挥标准化效益。实现经济、社会、生态效益的共赢, 推动和实 现高质量发展, 是绿色发展理念的价值取向。绿色水电站的标准化建设, 其目的同样是实现经济、社会、生态效益的共赢。应通过水电站标准化建 设, 强化其功能结构的丰富性、功能释放的多样性。在经济上, 应通过水电 站标准化建设推动其增值的持续性 ${ }^{[6]}$, 比如, 在安全生产标准化建设方面, 通过建立完善安全生产机制、机组扩容改造、消除事故隐患, 可实现水电 站持续性的增值。在生态上, 应通过水电站标准化建设改善和优化生态环 境。比如, 河北平山县秘家会水电站, 在其标准化建设中, 通过在枯水期将 生态基流控制在 $\geqslant 2 \mathrm{~m}^{3} / \mathrm{s}$, 最大程度地减少对减水河道的影响。在社会上, 应通过水电站标准化建设充分释放其社会服务功能, 仍以秘家会水电站为 例, 针对当地群众农田灌溉分散、浪费人力物力问题, 该水电站将灌溉模式 从分散变为集中, 不仅给群众带来了实惠, 而且节约的水源可代发电 300 多 万 $\mathrm{kW} \cdot \mathrm{h}$; 同时, 并支出 1000 多万元解决当地民众的实际困难。

总之, 推动水电站标准化建设与发展, 具有极其重要的现实意义。应基 于绿色发展理念, 结合当地地理资源和生态实际, 加强水电站标准化建设, 并通过标准化建设, 推动水电站安全化、高效化、创新化、和谐化、秀美 化发展, 从而实现水电站与自然生态、社会生态和谐共生的局面。

\section{[参考文献]}

[1]渠彦超,张晓东.绿色发展理念的伦理内涵与实现路径[J].青海社 会科学,2016(3):54-58.

[2]王超,李大伟,王芬,等.标准化的经济效益——德国调查研究结果综 述[J].工程建设标准化,2006(4):17-20.

[3]刘建文,潘丽枫.农村水电站标准化建设的实践与思考[J].中国水能 及电气化,2011(4):31-32.

[4]赵立强.推进质量标准化建设[J].施工企业管理,2016(6):56-57.

[5]季健康.浙江省农村水电站标准化建设的实践与探索[J].浙江水利 科技,2016(5):29-31.

[6]苏磊, 张志文. 严格安全生产标准化推动电站持续性增值[J].河北水 利,2016(1):29. 